\title{
Chapter 5 \\ Precise Measurements of Neutron Capture Cross Sections for LLFPs and MAs
}

\author{
S. Nakamura, A. Kimura, M. Ohta, T. Fujii, S. Fukutani, K. Furutaka, \\ S. Goko, H. Harada, K. Hirose, J. Hori, M. Igashira, T. Kamiyama, \\ T. Katabuchi, T. Kin, K. Kino, F. Kitatani, Y. Kiyanagi, M. Koizumi, \\ M. Mizumoto, M. Oshima, K. Takamiya, Y. Toh, and H. Yamana
}

\begin{abstract}
To evaluate the feasibility of development of nuclear transmutation technology and an advanced nuclear system, precise nuclear data of neutron capture cross sections for long-lived fission products (LLFPs) and minor actinides (MAs) are indispensable. In this chapter, we present our research activities for the measurements of neutron capture cross sections for LLFPs and MAs.
\end{abstract}

Keywords Activation method - ANNRI $・$ J-PARC $\bullet$ Long-lived fission products

- Minor actinides $\bullet$ Neutron capture cross section $\bullet$ Time-of-flight method

\footnotetext{
S. Nakamura $(\bowtie) \bullet$ A. Kimura • M. Ohta • K. Furutaka • S. Goko • H. Harada • K. Hirose T. Kin • F. Kitatani • M. Koizumi • Y. Toh

Japan Atomic Energy Agency, 2-4 Shirane, Shirakata, Tokai-mura, Naka-gun, Ibaraki 319-1195, Japan

e-mail: nakamura.shoji@jaea.go.jp

T. Fujii • S. Fukutani • J. Hori • K. Takamiya • H. Yamana

Research Reactor Institute, Kyoto University, 2-1010 Asashiro Nishi, Kumatori-cho, Sennan-gun, Osaka 590-0494, Japan

M. Igashira • T. Katabuchi • M. Mizumoto

Research Laboratory for Nuclear Reactors, Tokyo Institute of Technology, O-okayama, Meguro, Tokyo 152-8550, Japan

T. Kamiyama $\bullet$ K. Kino

Faculty of Engineering, Hokkaido University, Kita 13, Nishi 8, Kita-ku, Sapporo 060-8628, Japan

Y. Kiyanagi

Faculty of Engineering, Hokkaido University, Kita 13, Nishi 8, Kita-ku,

Sapporo 060-8628, Japan

Nagoya University, Furo-cho, Chikusa-ku, Nagoya 464-8601, Japan

M. Oshima

Japan Atomic Energy Agency, 2-4 Shirane, Shirakata, Tokai-mura, Naka-gun,

Ibaraki 319-1195, Japan

Japan Chemical Analysis Center, 295-3 Sannou-cho, Inage-ku, Chiba-city,

Chiba 263-0002, Japan 


\subsection{Introduction}

Associated with the social acceptability of nuclear power reactors, it is desirable to solve the problems of nuclear waste management of the long-lived fission products (LLFPs) and minor actinides (MAs) existing in spent nuclear fuels. A method of nuclear transmutation seems to be one of the solutions to reduce the radiotoxicity of nuclear wastes. The transmutation method makes it possible to reduce both the size of a repository for packages of nuclear wastes and the storage risks for the long term. To evaluate the feasibility of development of the nuclear transmutation method, precise nuclear data of neutron capture cross sections for LLFPs and MAs are indispensable.

This chapter presents joint research activities by JAEA and universities for measurements of the neutron capture cross sections for LLFPs and MAs by activation and neutron time-of-flight (TOF) methods.

\subsection{Present Situation of Data for LLFPs and MAs}

Although accurate data of neutron capture cross sections are necessary to evaluate reaction rates and burn-up times, there are discrepancies among the reported data for the thermal neutron capture cross sections for LLFPs and MAs. As an example of MA, Fig. 5.1 shows the trend of the thermal neutron capture cross section data for ${ }^{237} \mathrm{~Np}$ : the discrepancies are about $10 \%$. Discrepancies between experimental and evaluated data still remain. As for LLFPs, e.g., ${ }^{93} \mathrm{Zr}$, Fig. 5.2 shows that there

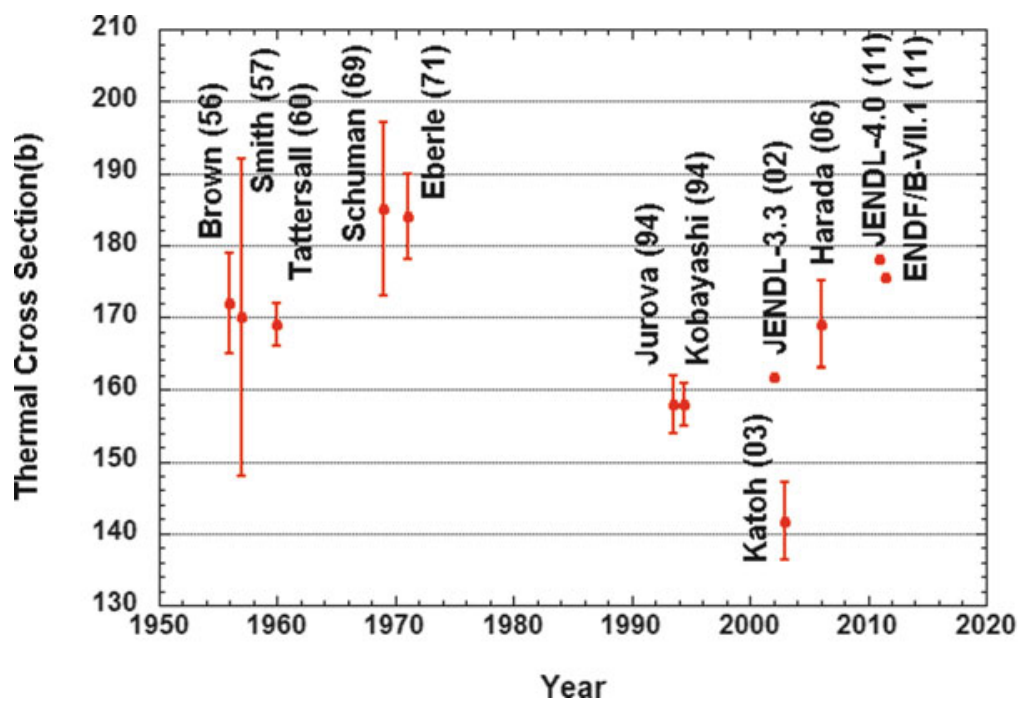

Fig. 5.1 Trend of thermal neutron capture cross section of ${ }^{237} \mathrm{~Np}$ from the $1950 \mathrm{~s}$ 


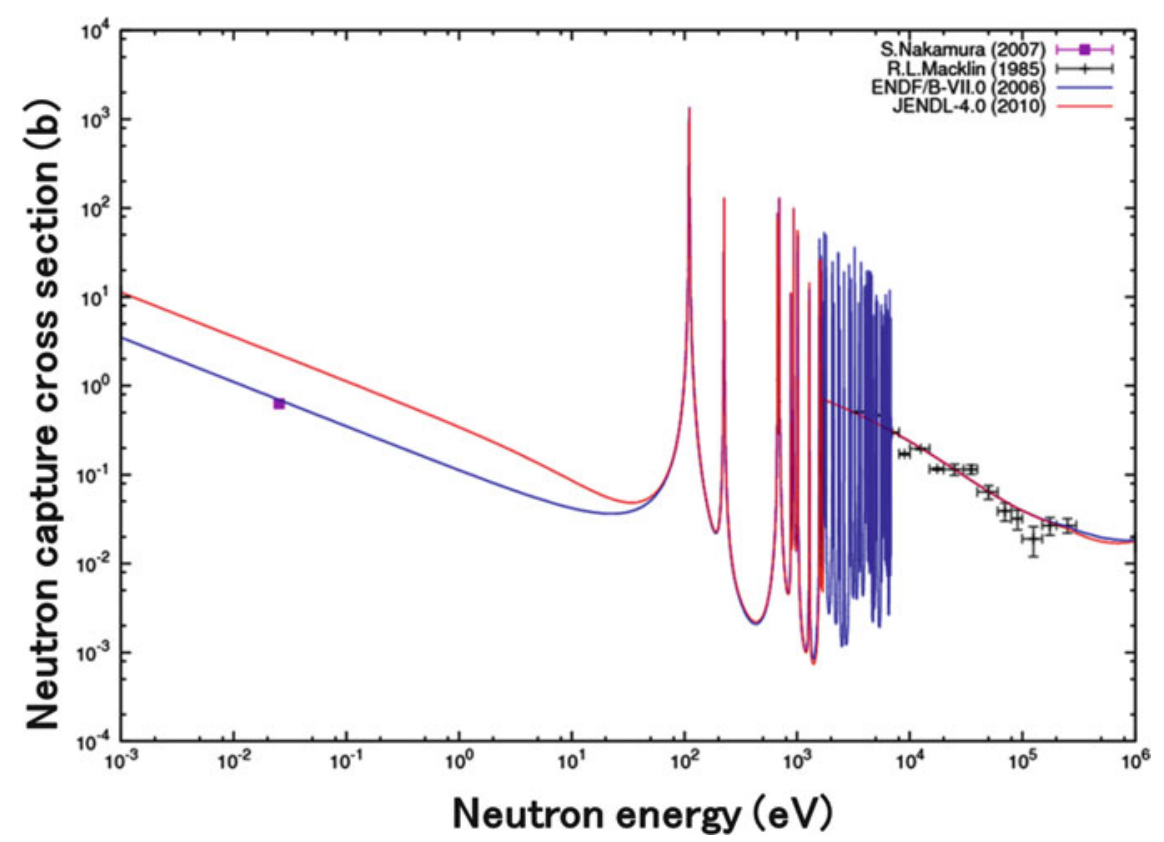

Fig. 5.2 Present situation of cross-section data for ${ }^{93} \mathrm{Zr}$

are discrepancies between ENDF/B-VII.0 and JENDL-4.0 evaluations in the region of the thermal neutron energy. Thus, our concern was focused to remeasure the neutron capture cross sections of those LLFPs and MAs.

\subsection{Measurement Activities by the Activation Method}

Neutron capture cross sections were determined on the basis of Westcott's convention [1] by an activation method. The results for LLFPs [2-23] are listed in Table 5.1, and for MAs [24-31] in Table 5.2, together with previously reported data. Here, the symbols $\sigma_{\text {eff }}, \sigma_{0}$, and $I_{0}$ denote the effective cross section, the thermal neutron capture cross section, and the resonance integral, respectively; $\sigma_{0}$ is the cross section at the neutron energy of $25.3 \mathrm{meV}$.

Nuclear waste sometimes contains a large amount of stable nuclei having the same atomic number as that of long-lived fission products. These stable nuclei absorb thermal neutrons during the neutron irradiation of the nuclear waste and affect the neutron economics; the reaction rate of the target nuclei is reduced. Moreover, some of these stable nuclei breed more radioactive nuclei by the neutron capture process. It is also necessary for transmutation study to accurately estimate these influences caused by stable nuclei involved in the FP targets. The cross sections of the stable nuclei, such as ${ }^{127} \mathrm{I}$ [14] and ${ }^{133} \mathrm{Cs}$ [20], were also measured; the results are shown in Table 5.1. 
Table 5.1 Results of thermal neutron capture cross sections and resonance integrals for longlived fission products (LLFPs)

\begin{tabular}{|c|c|c|}
\hline Nuclide (half-life) & Reported data (author, year) & JAEA data \\
\hline \multirow[t]{2}{*}{${ }^{137} \mathrm{Cs}$ (30 years) } & \multirow{2}{*}{$\begin{array}{l}\sigma_{\text {eff }}=0.11 \pm 0.03 \mathrm{~b} \text { (Stupegia } \\
1960[2])\end{array}$} & $\sigma_{0}=0.25 \pm 0.02 \mathrm{~b}$ \\
\hline & & $\begin{array}{l}I_{0}=0.36 \pm 0.07 \mathrm{~b}(1990,1993,2000 \\
[3-5])\end{array}$ \\
\hline \multirow[t]{4}{*}{${ }^{90} \mathrm{Sr}$ (29 years) } & \multirow{4}{*}{$\begin{array}{l}\sigma_{\text {eff }}=0.8 \pm 0.5 \mathrm{~b}(\text { Zeisel } 1966 \\
[6])\end{array}$} & $\sigma_{0}=10.1 \pm 1.3 / 4.2 \mathrm{mb}$ \\
\hline & & $I_{0} \leq 0.16 \mathrm{~b}(1994[7])$ \\
\hline & & $\sigma_{0}=10.1 \pm 1.3 \mathrm{mb}$ \\
\hline & & $I_{0}=104 \pm 16 \mathrm{mb}(2001[8])$ \\
\hline \multirow{2}{*}{$\begin{array}{l}{ }^{99} \mathrm{Tc} \\
\left(2.1 \times 10^{5} \text { years }\right)\end{array}$} & $\sigma_{0}=20 \pm 2 \mathrm{~b}$ & $\sigma_{0}=22.9 \pm 1.3 \mathrm{~b}$ \\
\hline & $I_{0}=186 \pm 16$ b (Lucas $\left.1977[9]\right)$ & $I_{0}=398 \pm 38 \mathrm{~b}(1995[10])$ \\
\hline \multirow{2}{*}{$\begin{array}{l}{ }^{129} \mathrm{I} \\
\left(1.6 \times 10^{7} \text { years }\right)\end{array}$} & $\sigma_{0}=27 \pm 2 \mathrm{~b}$ & $\sigma_{0}=30.3 \pm 1.2 \mathrm{~b}$ \\
\hline & $\begin{array}{l}I_{0}=36 \pm 4 \mathrm{~b} \text { (Eastwood } 1958 \\
[11])\end{array}$ & $I_{0}=33.8 \pm 1.4 \mathrm{~b}(1996[12])$ \\
\hline \multirow[t]{2}{*}{${ }^{127}$ I (Stable) } & $\sigma_{0}=4.7 \pm 0.2 \mathrm{~b}$ & $\sigma_{0}=6.40 \pm 0.29 \mathrm{~b}$ \\
\hline & $\begin{array}{l}I_{0}=109 \pm 5 \mathrm{~b}(\text { Friedman } 1983 \\
[13])\end{array}$ & $I_{0}=162 \pm 8 \mathrm{~b}(1999[14])$ \\
\hline \multirow{2}{*}{$\begin{array}{l}{ }^{135} \mathrm{Cs} \\
\left(3 \times 10^{6} \text { years }\right)\end{array}$} & $\sigma_{0}=8.7 \pm 0.5 \mathrm{~b}$ & $\sigma_{0}=8.3 \pm 0.3 \mathrm{~b}$ \\
\hline & $\begin{array}{l}I_{0}=61.7 \pm 2.3 \mathrm{~b}(\text { Baerg } 1958 \\
[15])\end{array}$ & $I_{0}=38.1 \pm 2.6 \mathrm{~b}(1997[16])$ \\
\hline${ }^{134}$ Cs (2 years) & $\begin{array}{l}\sigma_{\text {eff }}=134 \pm 12 \text { b (Bayly } 1958 \\
[17])\end{array}$ & $\sigma_{\mathrm{eff}}=141 \pm 9 \mathrm{~b}(1999[18])$ \\
\hline \multirow[t]{2}{*}{${ }^{133} \mathrm{Cs}$ (Stable) } & $\sigma_{0}=30.4 \pm 0.8 \mathrm{~b}$ & $\sigma_{0}=29.0 \pm 1.0 \mathrm{~b}$ \\
\hline & $I_{0}=461 \pm 25 \mathrm{~b}($ Baerg 1960 [19]) & $I_{0}=298 \pm 16 \mathrm{~b}(1999[20])$ \\
\hline \multirow{3}{*}{$\begin{array}{l}{ }^{166 \mathrm{~m}} \mathrm{Ho} \\
\left(1.2 \times 10^{3} \text { years }\right)\end{array}$} & $\sigma_{0}=9,140 \pm 650 \mathrm{~b}$ & $\sigma_{\text {eff }}=3 \pm 1 \mathrm{~kb}(2000[22])$ \\
\hline & \multirow{2}{*}{$\begin{array}{l}I_{0}=1,140 \pm 90 \mathrm{~b} \text { (Masyanov } \\
1993[21])\end{array}$} & $\sigma_{0}=3.11 \pm 0.82 \mathrm{~kb}$ \\
\hline & & $I_{0}=10.0 \pm 2.7 \mathrm{~kb}(2002[23])$ \\
\hline
\end{tabular}

Table 5.2 Results of thermal neutron capture cross sections and resonance integrals for minor actinides (MAs)

\begin{tabular}{|c|c|c|}
\hline Nuclide (half-life) & Reported data (author, year) & JAEA data \\
\hline \multirow{3}{*}{$\begin{array}{l}{ }^{237} \mathrm{~Np} \\
\left(2.14 \times 10^{6} \text { years }\right)\end{array}$} & $\sigma_{0}=158 \pm 3 \mathrm{~b}$ & $\sigma_{0}=141.7 \pm 5.4 \mathrm{~b}$ \\
\hline & \multirow{2}{*}{$I_{0}=652 \pm 24$ b (Kobayashi 1994 [24]) } & $I_{0}=862 \pm 51 \mathrm{~b}(2003[25])$ \\
\hline & & $\sigma_{0}=169 \pm 6 \mathrm{~b}(2006[26])$ \\
\hline${ }^{238} \mathrm{~Np}$ (2.1 days) & No data & $\begin{array}{l}\sigma_{\text {eff }}=479 \pm 24 \mathrm{~b}(2004 \\
[27])\end{array}$ \\
\hline \multirow[t]{2}{*}{${ }^{241}$ Am (432 years) } & $\sigma_{0, \mathrm{~g}}=768 \pm 58 \mathrm{~b}$ & $\sigma_{0, \mathrm{~g}}=628 \pm 22 \mathrm{~b}$ \\
\hline & $\begin{array}{l}I_{0, \mathrm{~g}}=1,694 \pm 146 \mathrm{~b} \text { (Shinohara } 1997 \\
[28])\end{array}$ & $\begin{array}{l}I_{0, \mathrm{~g}}=3.5 \pm 0.3 \mathrm{~kb}(2007 \\
[29])\end{array}$ \\
\hline \multirow[t]{2}{*}{${ }^{243} \mathrm{Am}(7,370$ years $)$} & $\sigma_{0, \mathrm{~m}}=80 \mathrm{~b}$ & \multirow{2}{*}{$\begin{array}{l}\sigma_{\text {eff }}=174.0 \pm 5.3 \mathrm{~b}(2006 \\
[31])\end{array}$} \\
\hline & $\sigma_{0, \mathrm{~g}}=84.3 \mathrm{~b}($ Ice $1966[30])$ & \\
\hline
\end{tabular}

As seen in Table 5.1, the thermal cross section for ${ }^{137} \mathrm{Cs}$ is about twice as large as the previous data reported by Stupegia [2]. As for ${ }^{90} \mathrm{Sr}$, its thermal cross section is 
found to be much smaller than the data reported by Zeisel [6]. As seen in Table 5.2, the cross section of ${ }^{238} \mathrm{~Np}$ is obtained for the first time. Thus, the joint research activities of the Japan Atomic Energy Agency (JAEA) and universities have measured the cross sections for important LLFPs and MAs by the activation method.

\subsection{Measurement Activities at J-PARC/MLF/ANNRI}

A new experimental apparatus called the accurate neutron nucleus reaction measurement instrument (ANNRI) has been constructed on the beam line no. 4 (BL04) of the MLF in the J-PARC. The ANNRI has two detector systems. One of them is a large Ge detector array, which consists of two cluster-Ge detectors, eight coaxialshaped Ge detectors, and BGO Compton suppression detectors; the other is a large $\mathrm{NaI}(\mathrm{Tl})$ spectrometer (Fig. 5.3). The ANNRI has an advantage for neutron crosssection measurements because the MLF facility can provide the strongest neutron intensity in the world.

The neutron capture cross sections of ${ }^{237} \mathrm{~Np}[32,33],{ }^{241} \mathrm{Am}[34],{ }^{244} \mathrm{Cm}[35]$, ${ }^{93} \mathrm{Zr}$ [36], ${ }^{99} \mathrm{Tc}$ [37], and ${ }^{107} \mathrm{Pd}[38]$ have been measured relative to the ${ }^{10} \mathrm{~B}(\mathrm{n}, \alpha \gamma)$ standard cross section by the TOF method. Some highlights of results obtained in our research activities are shown in Fig. 5.4 for ${ }^{237} \mathrm{~Np}$ and in Fig. 5.5 for ${ }^{93} \mathrm{Zr}$.

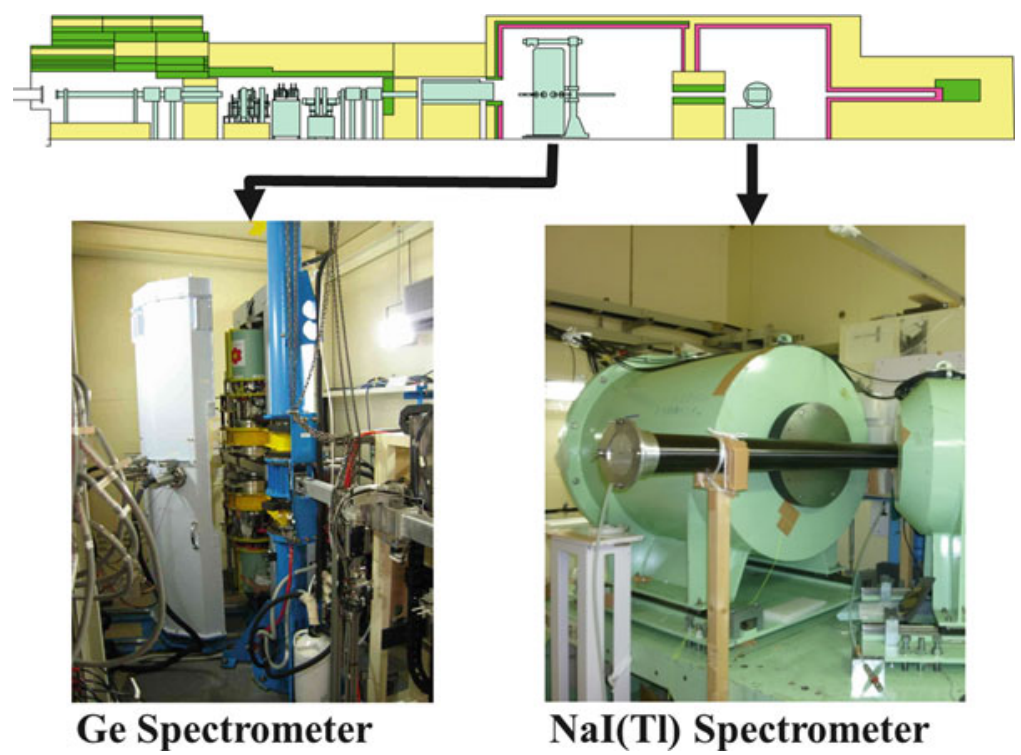

Fig. 5.3 A new experimental apparatus called the accurate neutron nucleus reaction measurement instrument (ANNRI). The cross-sectional view of ANNRI is shown in the upper panel, the spectrometer is on the left side, and the $\mathrm{NaI}(\mathrm{Tl})$ spectrometer is on the right side 


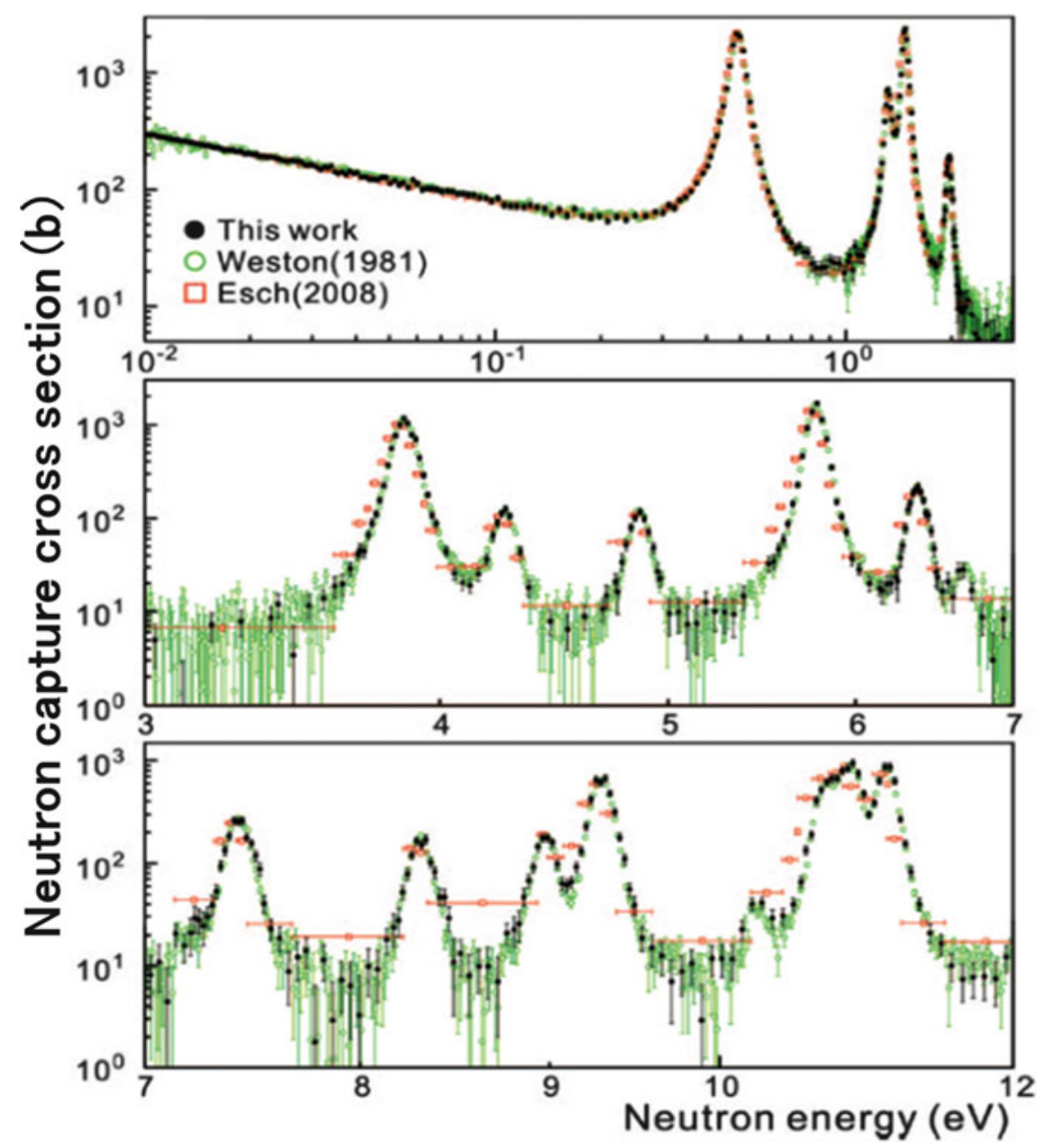

Fig. 5.4 ${ }^{241} \mathrm{Am}$ cross section in neutron energy from 0.01 to $10 \mathrm{eV}$

The results obtained at the ANNRI are good agreement with the data reported by Weston (Fig. 5.4). The ${ }^{93} \mathrm{Zr}$ cross sections in Fig. 5.5 present results greatly different from the evaluated data in the thermal neutron energy region. One finds that the present results support the value of the thermal cross section reported in 2007 [39].

\subsection{Summary}

This chapter described the JAEA research activities for the measurement of neutron capture cross sections for LLFPs and MAs by activation and neutron time-of-flight (TOF) methods. We summarized our results of the thermal neutron capture cross 


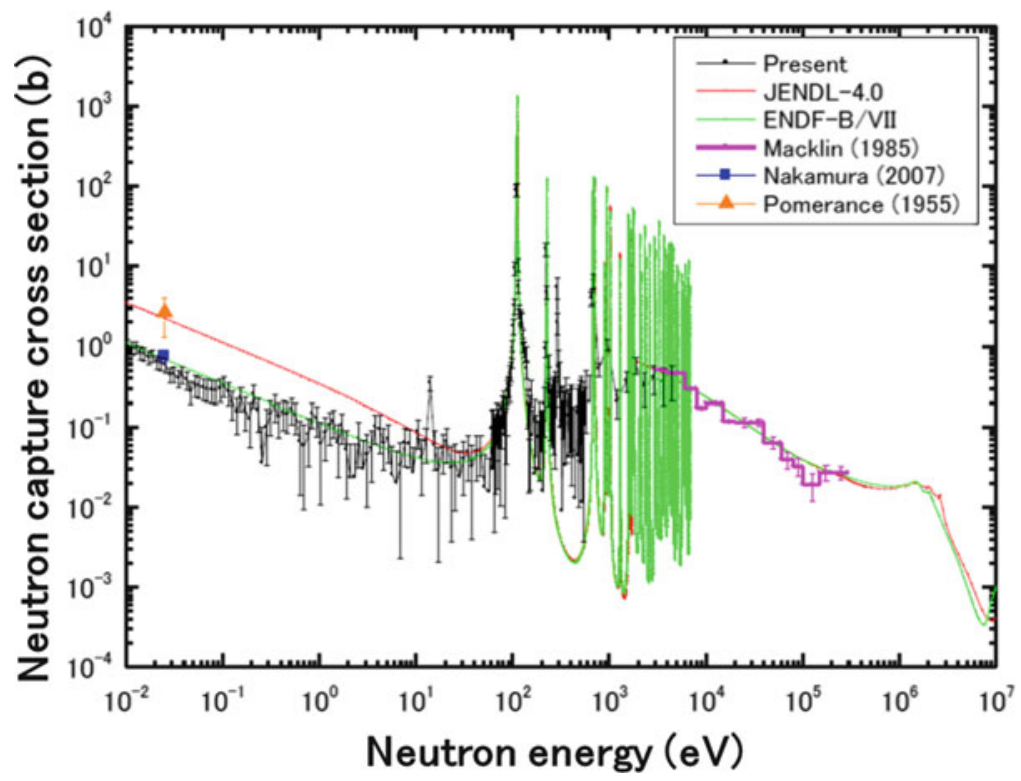

Fig. 5.5 ${ }^{93} \mathrm{Zr}$ cross section (tentative data) together with the evaluated data

section and the resonance integral for some of the important LLFPs and MAs by the activation method.

Operation of a new experimental apparatus called the accurate neutron nucleus reaction measurement instrument (ANNRI) in the MLF at J-PARC has been started for neutron capture cross-section measurements of MAs and LLFPs. Some of the highlights of our results have been shown here.

Acknowledgments The authors thank the staff at Kyoto University Reactor Institute, Rikkyo University Reactor and JRR-3M. A part of this work has been carried out under the Visiting Researcher's Program of the Research Reactor Institute, Kyoto University. Moreover, the authors appreciate the accelerator staff of J-PARC for their operation of the accelerator.

This work is supported by JSPS KAKENHI (22226016).

Open Access This chapter is distributed under the terms of the Creative Commons Attribution Noncommercial License, which permits any noncommercial use, distribution, and reproduction in any medium, provided the original author(s) and source are credited.

\section{References}

1. Westcott $\mathrm{CH}$ et al (1958) Proceedings of 2nd International Conference on Peaceful Uses of Atomic Energy, Geneva, vol 16, United Nations, New York, p. 70

2. Stupegia DC (1960) J Nucl Energ A12:16

3. Harada H et al (1990) J Nucl Sci Technol 27(6):577 
4. Sekine T et al (1993) J Nucl Sci Technol 30(11):1099

5. Wada H et al (2000) J Nucl Sci Technol 37(10):827

6. Zeisel G (1966) Acta Phys Austr 23:5223

7. Harada H et al (1994) J Nucl Sci Technol 31(3):173

8. Nakamura S et al (2001) J Nucl Sci Technol 38(12):1029

9. Lucas $\mathrm{M}$ et al (1977) IAEA-TC-119/14, p 407-432

10. Harada $\mathrm{H}$ et al (1995) J Nucl Sci Technol 32(5):395

11. Eastwood TA et al (1958) Proceedings of 2nd International Conference on Peaceful Uses of Atomic Energy, Geneva, vol 16. United Nations, New York, p 54

12. Nakamura $S$ et al (1996) J Nucl Sci Technol 33(4):283

13. Friedmann L et al (1983) Radiochim Acta $33: 182$

14. Nakamura S et al (1999) J Nucl Sci Technol 36(3):223

15. Baerg AP et al (1958) Can J Phys 36:863

16. Katoh T et al (1997) J Nucl Sci Technol 34(5):431

17. Bayly JG et al (1958) Inorg Nucl Chem 5:259

18. Katoh T et al (1999) J Nucl Sci Technol 36(8):635

19. Baerg AP et al (1960) Can J Chem 38:2528

20. Nakamura S et al (1999) J Nucl Sci Technol 36(10):847

21. Masyanov SM et al (1993) Atom Energ 73:673

22. Harada H et al (2000) J Nucl Sci Technol 37(9):821

23. Katoh T et al (2002) J Nucl Sci Technol 39(7):705

24. Kobayashi K et al (1994) J Nucl Sci Technol 31(12):1239

25. Katoh T et al (2003) J Nucl Sci Technol 40(8):559

26. Harada H et al (2006) J Nucl Sci Technol 43(11):1289

27. Harada H et al (2004) J Nucl Sci Technol 41(1):1

28. Shinohara N et al (1997) J Nucl Sci Technol 34(7):613

29. Nakamura $S$ et al (2007) J Nucl Sci Technol 44(12):1500

30. Ice CH (1966) Du Pont: Savannah River reports, vol 66, p 69

31. Ohta M et al (2006) J Nucl Sci Technol 43(12):1441

32. Hirose K et al. (2014) Nuclear Data Sheets 119:48-51

33. Hirose K et al (2013) J Nucl Sci Technol 50:188-200

34. Harada $\mathrm{H}$ et al (2014) Nuclear Data Sheets 119:61-64

35. Kimura A et al (2012) J Nucl Sci Technol 49:708-724

36. Hori J et al (2011) J Korean Phys Soc 59(2):1777-1780

37. Kino K et al (2014) Nuclear Data Sheets 119:140-142

38. Nakamura $S$ et al (2014) Nuclear Data Sheets 119:143-146

39. Nakamura $S$ et al (2007) J Nucl Sci Technol 44(1):21 